\title{
INFESTAÇÃO DE ERVA-DE-PASSARINHO (Phoradendron affine, (Pohl ex dc.) Engl. \& Krause - Viscaceae) EM ESPÉCIES ARBÓREAS NO PARQUE DO POVO DE PRESIDENTE PRUDENTE - SP.
}

Rubens Moia Junior; Johnny Michael Santos da Silva, André Vieira Gonçalves, Luiz Waldemar de Oliveira.

Universidade do Oeste Paulista UNOESTE - curso de Ciências Biológicas, Presidente Prudente, SP. E-mail: rubens_bio@hotmail.com

\section{RESUMO}

Este trabalho teve como objetivo observar a infestação de erva-de-passarinho no Parque do Povo, município de Presidente Prudente/SP, identificando sua espécie, assim como o hospedeiro desse parasita. Foram realizadas observações com binóculo e os dados de espécime e hospedeiros foram organizados em planilhas e identificados através de guias florísticos. Na área de amostragem apenas uma espécie observada parasitando as árvores, sendo identificada como Phoradendron affine. O hemiparasita foi visto parasitando duas espécies de árvores, o ipê-roxo, Handroanthus avellanedae - Bignoniaceae, e santa-bárbara, Melia azedarach - Meliaceae. Foi constatada a presença da erva-de-passarinho em 62 indivíduos, sendo 57 espécimes de Handroanthus avellanedae e 5 espécimes de Melia azedarach. Apenas um indivíduo de Melia azedarach apresentou sanidade afetada, os demais não apresentaram alterações visíveis. Phoradendron affine infestou $100 \%$ dos indivíduos de Melia azedarach, o que não ocorreu com Handroanthus avellanedae, nem todos possuíam o parasita. Sendo assim, Phoradendron affine não apresenta padrão de infestação.

Palavras-chave: Hemiparasita. Erva-de-passarinho. Viscacea. Arborização urbana. Handroanthus. Meliaceae.

INFESTATION OF BIRD GRASS (Phoradendron affine, (Pohl ex dc.) Engl. \& Krause - Viscaceae) IN TREE SPECIES IN THE PARK OF THE PEOPLE OF PRESIDENTE PRUDENTE - SP.

\begin{abstract}
This work was intended to observe the infestation of bird grass in the people's Park, the municipality of Presidente Prudente/SP, identifying its species, as well as the host of this parasite. Observations were made with binoculars and the specimen and host data were organized into spreadsheets and identified through floristic guides. In the sampling area only one observed species parasite the trees, being identified as Phoradendron affine. The mistletoe was seen parasite two species of trees, the ipê-roxo, Handroanthus avellanedae - Bignoniaceae, and santabárbara, Melia azedarach - Meliaceae. The presence of the bird grass was found in 62 individuals, with 57 specimens of Handroanthus avellanedae and 5 specimens of Melia azedarach. Only one individual of Melia azedarach presented sanity affected, the others did not present any visible changes. Phoradendron affine infested $100 \%$ of the individuals of Melia azedarach, which did not occur with Handroanthus avellanedae, not all possessed the parasite. Thus, Phoradendron affine does not present an infestation pattern.
\end{abstract}

Keywords: Mistletoe. Bird-grass. Viscacea. Urban forestry. Handroanthus. Meliaceae. 


\section{INTRODUÇÃO E OBJETIVO}

As áreas verdes são fundamentais na qualidade ambiental urbana, por assumirem importante papel no equilíbrio de espaço modificado para o meio urbano e meio ambiente, atuando no equilíbrio da cidade, no conjunto dos fenômenos químicos e físicos com os elementos necessários para a vida [1,2].

Presidente Prudente localizado no oeste de São Paulo, estima-se que existem 147 áreas verdes na cidade. O Parque do Povo, considerada a maior área verde urbana da cidade, possui uma área total de $288.351,85 \mathrm{~m}^{2}[3,4]$. O Parque, antes considerado uma área degradada, passou por um processo de reurbanização com a criação de áreas verdes, desempenhando grande papel na organização da cidade, após a criação de áreas verdes o parque apresenta uma grande quantidade de espécies arbóreas, entre elas, com grande quantidade de indivíduos do Gênero Handroanthus $[4,5]$.

As árvores possuem papel importante nas vias urbanas, e podem ser avaliadas por meio de sua vitalidade, vigor taxa de crescimento, sendo de total importância avaliar suas condições contra infestações por pragas como a erva de passarinho, que são encontradas em todo o mundo, sendo considerada pragas que crescem em espécies agrícolas e por afetarem a qualidade das árvores no meio urbano [6,7]. Conhecidas popularmente como erva-de-passarinho, são espécies botânicas hemiparasitas composta pela família; Loranthaceae é composta por 40 gêneros e 1.500 espécies, distribuídas em regiões tropicais e subtropicais, entre os gêneros gerontogéos destacam-se Loranthus (500 spp) e Viscum (65 spp) e entre os neogéos, Psittacanthus (80 spp), Phthirusa (55 spp), Struthanthus (60 spp) e Phoradendron (300 spp), Família Viscaceae possui cerca de 520 espécies dentre os gêneros atualmente reconhecidos: Dendrophthora e Phoradendron, ambos os gêneros se diferencia unicamente pelo número de lóculos na antera, sendo dois em Phoradendron e um em Dendrophthora. $[8,9,10]$.

As plantas hemiparasitas crescem em galhos de árvores ou arbustos, podendo modificar a estrutura da comunidade onde estão inseridos, estabelecendo forte conexão com o xilema para retirar água e nutrientes dependendo parcialmente dos seus hospedeiros, diferente dos holoparasitas que dependem completamente dos recursos dos hospedeiros $[11,12,13]$. Pertencentes ao grupo dos hemiparasitas, as ervas-de-passarinho realizam sua própria fotossíntese, são plantas perenes, clorofiladas de folhas simples, são hermafroditas ou unissexuais, ocupam quase a totalidade da copa e suas raízes atravessam a casca, retirando água e nutrientes. Sua presença danifica árvores e arbustos, reduzindo a produção de frutos, diminuição do vigor, ataque de insetos, doenças e morte do ápice e até mesmo a morte do indivíduo $[14,15,16]$. São dependentes de aves para a dispersão de suas sementes, seus frutos são viscosos e suas sementes adocicadas, contribuindo para atrair aves, que se alimentam e colaboram na dispersão, as sementes ficam aderidas ao bico do pássaro levando para outras árvores ou através das fezes depositadas em galhos. Em algumas espécies são carregas pelo vendo ou por dispersão balística (onde o fruto explode arremessando as sementes) $[7,12,17]$. A dispersão se torna um fator crítico, uma vez que ela precisa se depositar em galhos hospedeiros suscetíveis para ter a chance de se estabelecer, no entanto, algumas ervas-de-passarinho podem parasitar uma variedade de hospedeiros, enquanto outras apresentam limitações, apenas parasitando uma única espécie, o gênero Phoradendron é conhecido por parasitar apenas uma única espécie de hospedeiro, sendo especialista em algumas regiões. [9,12]

O presente estudo teve como objetivo analisar a infestação de ervas-de-passarinho nas árvores do Parque do Povo de Presidente Prudente - SP, identificando as espécies de hemiparasitas e as espécies hospedeiras, realizando um levantamento das espécies hemiparasitas e seus respectivos hospedeiros, avaliar o grau de infestação, a sanidade das espécies arbóreas, e verificar se a altura das árvores possui relação com a quantidade de ervas-de-passarinho encontradas. 


\section{MÉTODOS}

A pesquisa foi realizada no parque do povo, uma área urbana no Município de Presidente Prudente, com área total de $288.351,85 \mathrm{~m}^{2}$ (Figura 1) e se estende desde a Avenida Brasil até a Avenida Manoel Goulart, com uma extensão aproximada de $2.800 \mathrm{~m}$ e perímetro aproximado de $5.900 \mathrm{~m}$, muito arborizada, possui extensos gramados, em seu entorno duas avenidas, a 14 de setembro e 11 de maio. Presidente Prudente (22 07' S e 51ㅇ 22' O, 421m de altitude) é um município do interior do estado de São Paulo, distante 558 quilômetros da capital estadual. Ocupa uma área de $562,107 \mathrm{~km}^{2}$, sendo $16,56 \mathrm{~km}^{2}$ são de área urbana. O clima é caracterizado como tropical chuvoso (tipo Aw segundo Köppen), com temperatura média anual de $22,7^{\circ} \mathrm{C}$, com inverno seco e frio, e verão chuvoso com temperaturas altas. A precipitação média anual é de $1.361 \mathrm{~mm} .[18]$

As observações e coletas foram realizadas no período de abril a julho de 2017 , fotografouse todos os indivíduos hospedeiros e alguns hemiparasitas com máquina digital semiprofissional e utilização de binóculos para localização dos hemiparasitas. Para medir a altura das arvores foi utilizado um teodolito caseiro (utilizado, uma porca com barbante na base central do transferidor de forma que ela fique com mobilidade) para a medição da altura, o primeiro passo consiste em mirar o transferidor na posição horizontal correspondente à base da árvore, fixando o teodolito. 0 segundo passo deslocar o barbante focando o ponto extremo da copa da árvore. A partir do ângulo indicado no transferidor é utilizado o cálculo: (Tangente $x$ distância até a árvore). Para aferir a circunferência a altura do peito (CAP) utilizou-se uma trena de 7,5 metros, o diâmetro a altura do peito foi calculado a partir da formula do perímetro da circunferência $(C=2 . \pi . r$ ), utilizando-se a circunferência obtida de cada indivíduo, todas as anotações foram registradas em planilhas.

A utilização da planilha fez-se necessária para anotar os dados propostos na pesquisa, Identificação de cada espécime arbóreo, sanidade, altura, circunferência do tronco na altura do peito (CAP), diâmetro do tronco na altura do peito (DAP), espécimes de hemiparasitas vivos, adultos e jovens, e espécimes de hemiparasitas mortos.

\section{RESULTADOS}

A espécie de erva-de-passarinho identificada parasitando as espécies arbóreas no parque do povo é Phoradendron affine - Viscacea (figura 1A, 1B; 2A, 2B). Segundo Dettke e Waechter (2014), este gênero compreende ervas monoico-diclinas, que ocorrem de forma agrupada sobre 0 hospedeiro; ramificação dicotômica, dicotomias causadas pelo aborto do meristema apical ou formação de inflorescências; ramos eretos; coloração castanha avermelhada, verde-escura até amarelada; preta, verde clara ou amarelada in sicco, e poucos ramos emergindo do sistema haustorial. Phoradendron affine pertence a família Viscacea, (Santalaceae), exclusiva do continente americano os gêneros Dendrophthora e Phoradendron. No Brasil o gênero Phoradendron apresenta uma maior diversidade com cerca de 60 espécies, sendo conhecido pelo fato de parasitar uma única espécie de hospedeiro em determinadas áreas. Dentre as espécies de árvores observadas no Parque do Povo 62 delas encontraram-se parasitadas por Phoradendron affine. Sendo elas Ipê-roxo (Handroanthus avellanedae - Bignoneaceae) e Santa-bárbara (Melia azedarach - Meliaceae). 


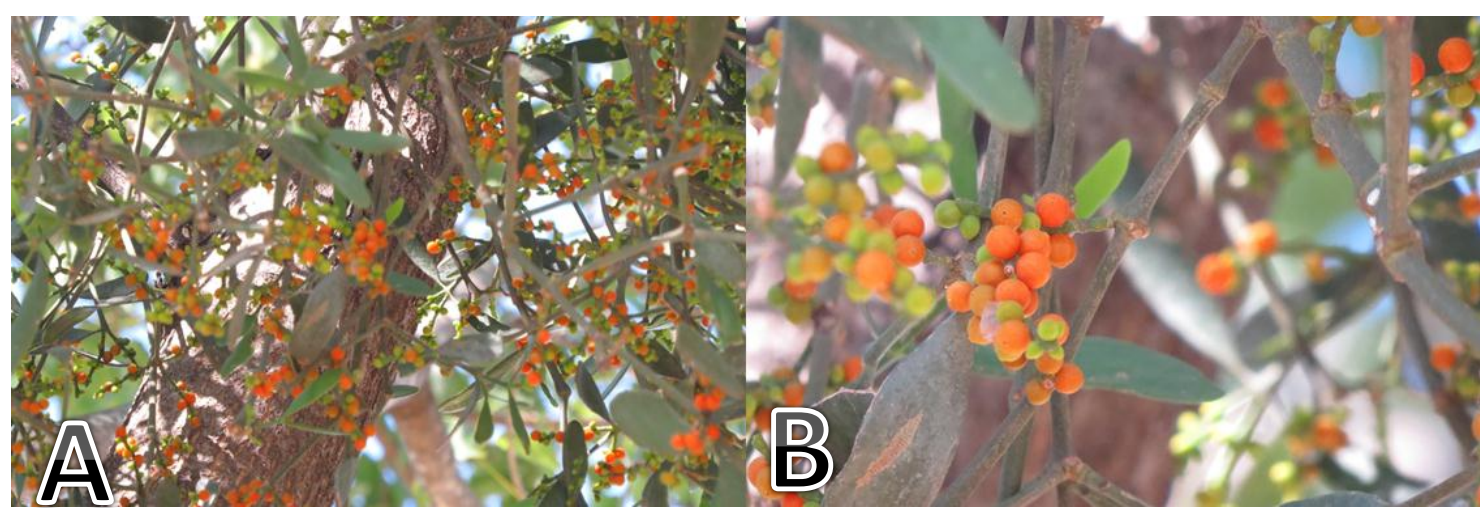

Figura 1. Indivíduo adulto de Phoradendron affine parasitando Handroanthus avellanedae. A: frutos maduros esféricos de cor alaranjada. B: disposição dos frutos ao longo dos ramos.

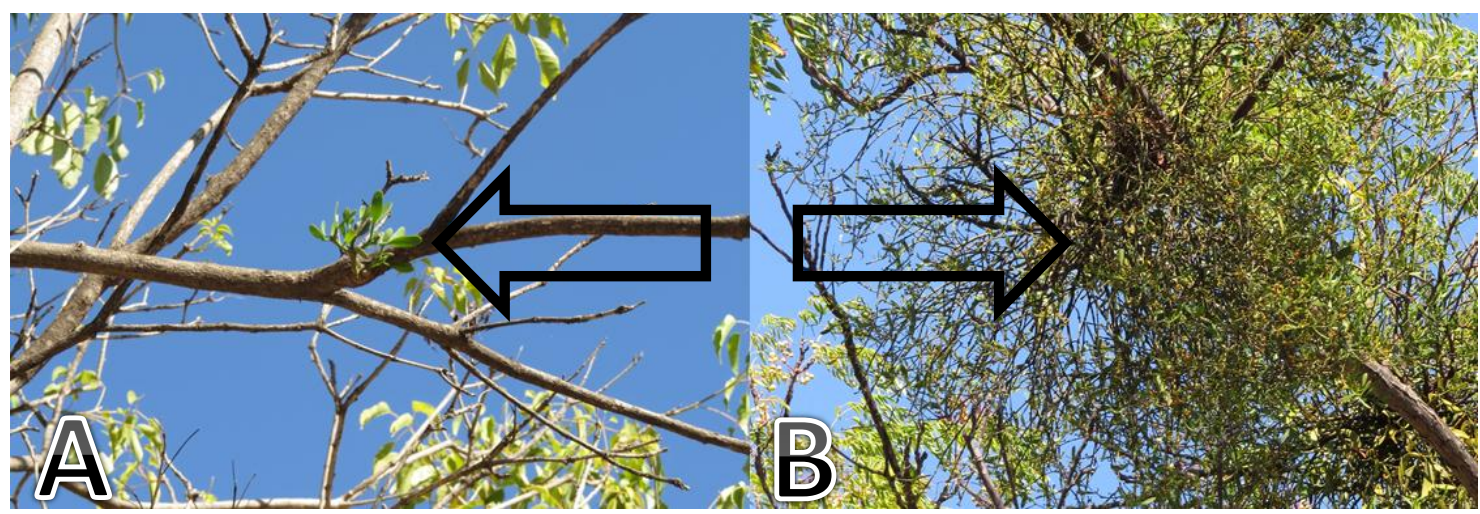

Figura 2. A: Indivíduo jovem de Phoradendron affine parasitando Handroanthus avellanedae. (seta). B: indivíduo adulto de Phoradendron affine parasitando Melia azedarach (seta), grande volume proporcionado por intensa ramificação e crescimento.

Phoradendron affine está presente em 57 indivíduos de Handroanthus avellanedae, geralmente em indivíduos com mais de 5 metros de altura (figura 3).

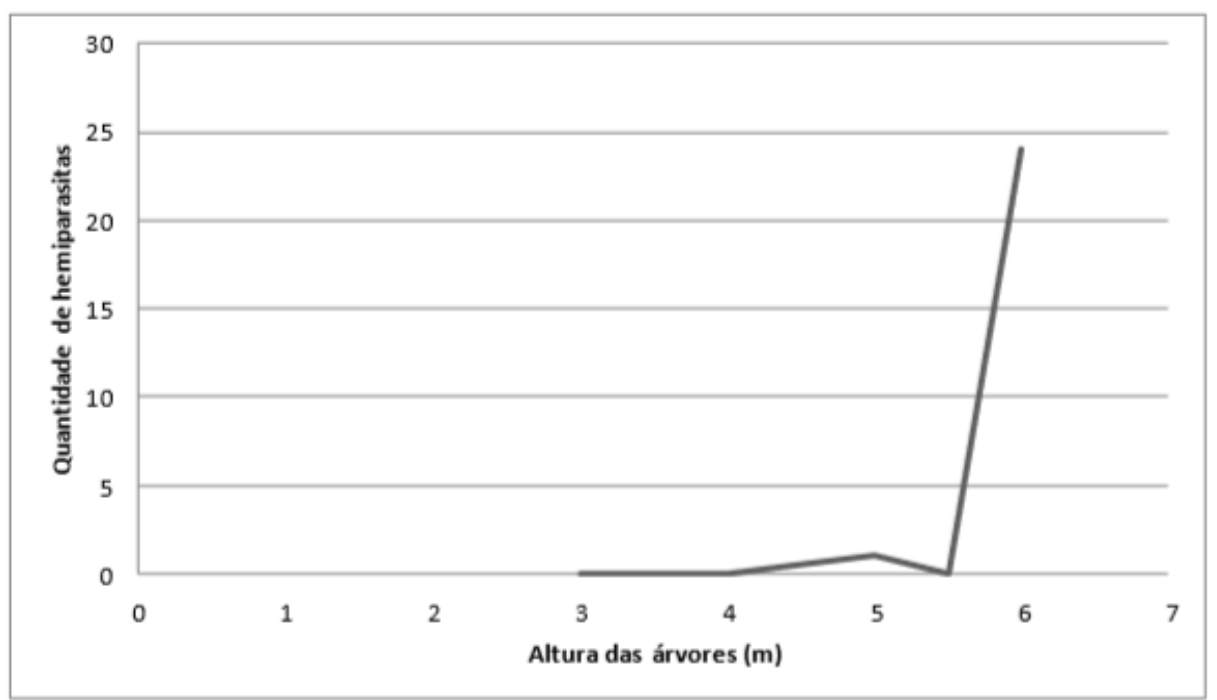

Figura 3: Gráfico da relação aparente entre quantidade de indivíduos de Phoradendron affine e altura das árvores.

Nos 62 hospedeiros, o número total de Phoradendron affine no Parque do Povo foi de 1.147, sendo 183 (16\%) indivíduos mortos. Do total de indivíduos vivos, 168 (14,6\%) são considerados jovens, com tamanho menor que $25 \mathrm{~cm}$ (figura 4). 


\section{HEMIPARASITAS}

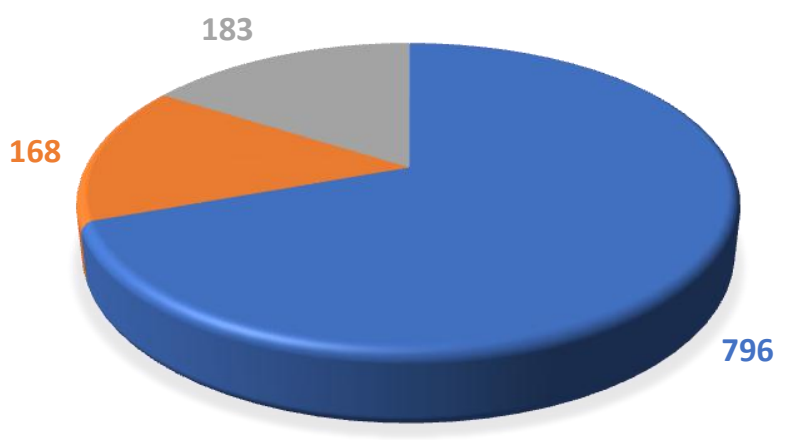

aADULTOS

GJOVENS

四MORTOS

Figura 4. Total de indivíduos de Phoradendron affine, indivíduos vivos 964 e mortos 183, totalizando 1147.

A maior infestação foi observada em um indivíduo de Melia azedarach, sendo encontrada em um único espécime, 83 indivíduos de Phoradendron affine. Indivíduos menores tendem a possuir menos parasitas, explicando a grande quantidade (30 indivíduos) de espécies parasitadas contendo entre 1 e 10 indivíduos de Phoradendron affine sendo 7 espécimes (11,2\%) de Handroanthus avellanedae parasitados por infestação única(Figura 5).

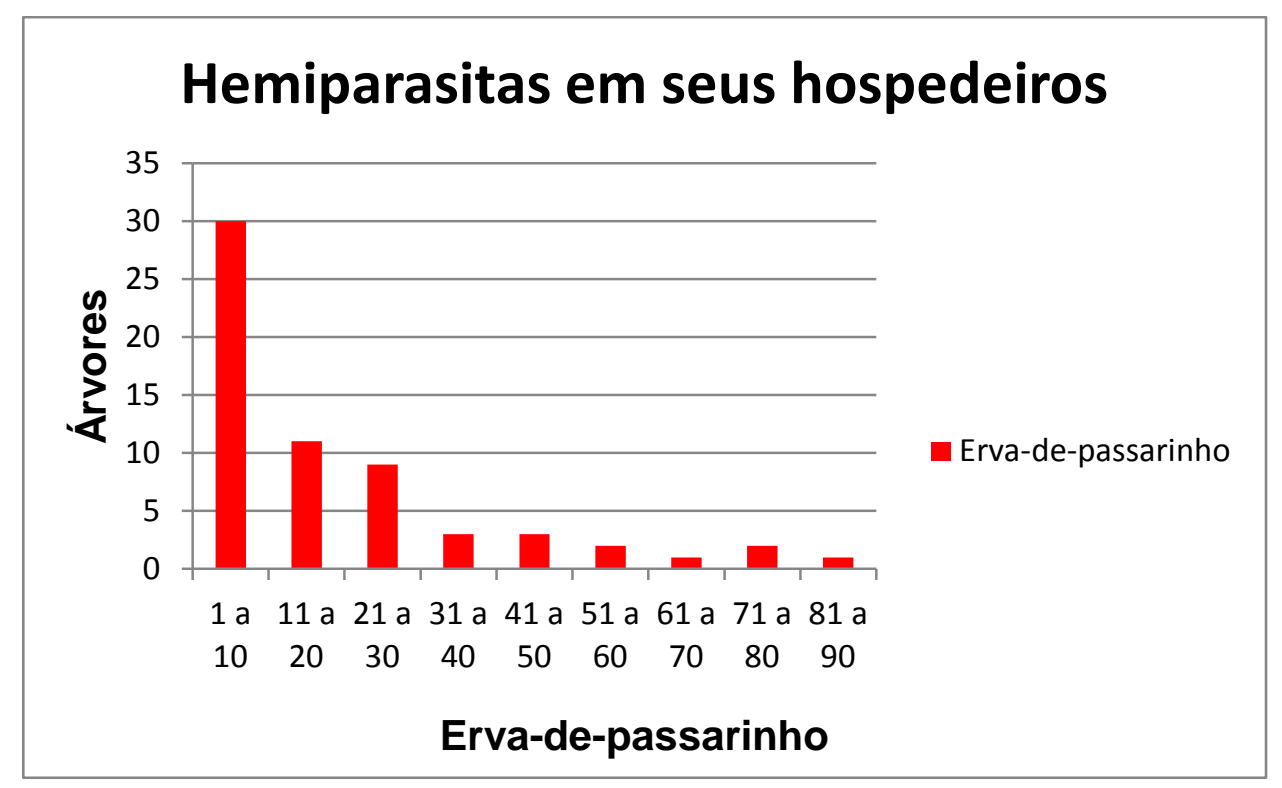

Figura 5. Relação quantidade de parasitas (Phoradendron affine) por hospedeiros (Handroanthus avellanedae e Melia azedarach).

Nos indivíduos de Handroanthus avellanedae não foram observados danos visíveis causados a nenhum dos indivíduos infestados por Phoradendron affine, estando os espécimes, aparentemente em ótima sanidade.

\section{DISCUSSÃO}

Phoradendron affine é a única espécie parasita encontrada em espécies arbóreas no parque do povo, situação que difere do estudo realizado por Caires e Proença (2008) na região do cerrado central, onde várias espécies do gênero Phoradendron foram identificadas, assim como no estado do Paraná onde foram registradas 14 espécies de Phoradendron [19], apesar deste gênero 
não ser, até o momento, identificado em Curitiba onde Leal et. al. (2006), identificaram apenas espécies do gênero Tripodanthus e Struthanthus parasitando as espécies arbóreas. A presença de apenas uma espécie de erva de passarinho, parasitando espécimes arbóreos no parque do povo, deve-se provavelmente por ser uma área urbana, onde a arborização não condiz com espécies essencialmente nativas, sendo uma área onde a arborização atendeu a aspectos mais ornamentais restringindo o sucesso de outras espécies de parasitas, até mesmo do gênero Phoradendron.

O fato de apenas duas espécies arbóreas, Handroanthus avellanedae (Ipê-roxo) espécie nativa, e Melia azedarach (Santa-bárbara), exótica, encontrarem-se parasitadas por Phoradendron affine no parque do povo, aponta para situações semelhantes, onde ambas provavelmente não apresentam meios de defesa eficaz contra a espécie parasita; estas espécies arbóreas possuem características como caule lenhoso, com cavidades na casca onde as sementes de Phoradendron affine são depositas e, germinando, atingem os tecidos condutores. A espécie Handroanthus avellanedae, nativa, assim como Phoradendron affine, coevoluiram e o sucesso do parasita pode estar relacionado a sua capacidade de superar as defesas desenvolvidas e selecionadas pelo hospedeiro, mesmo assim, vários são os indivíduos adultos de Handroanthus avellanedae que não apresentam-se parasitados, fato que requer mais estudos para esclarecer esta possível defesa apresentada, podendo estar relacionada a uma possível variabilidade genética na espécie. 0 parasitismo em Melia azedarach e em Handroanthus ssp tem sido relatado em outras regiões, tanto pelo gênero Phoradendron, como por outros gêneros de erva de passarinho $[14,19,20]$, sendo Melia azedarach uma espécie muito suscetível ao parasitismo, coincidindo com o que se observa no parque do povo, com $100 \%$ dos indivíduos parasitados e com alto grau de infestação. O sucesso de Phoradendron affine com relação ao parasitismo em todos os indivíduos de Melia azedarach possivelmente se deve a esta espécie arbórea, por ser exótica, não apresentar nenhuma forma de defesa desenvolvida contra um parasita nativo, o qual possui fácil dispersão e também meios eficazes de se estabelecer. Outras espécies nativas como Tabebuia roseoalba (ipê branco), Handroanthus albus (ipê amarelo), Caesalpinia leiostachya (pau ferro), Platypodium Elegans (amendoim do campo), Albizia niopoides (farinha seca), Jacaranda sp (jacarandá)Enterolobium contortisiliquum (orelha de macaco), Psidium guajava (goiaba), Eugenia uniflora (pitanga)e também exóticas Tamarindus indica (tamarindo), Tabebuia pentaphylla (Ipê rosa), Terminalia catappa (chapéu de sol), Licania tomentosa (oiti), Syzygium cumini (joão bolão), Eucalyptus, Pachira aquatica (monguba), Ficus benjamina e Ficus elastica (figueiras), Mangifera indica (manga) encontradas também no parque do povo não apresentam-se parasitadas.

Quanto maior o porte do hospedeiro, maior a quantidade de parasitas, possivelmente estando o parasita estabelecido, as aves dispersoras tendem a obter o fruto para sua alimentação e defecam nos caules, depositando as sementes. [21] Em um único exemplar de Melia azedarach foi observado 83 indivíduos de Phoradendron affine. Encontramos 1.147 indivíduos de Phoradendron affine, sendo 183 (16\%) indivíduos mortos e 168 (14,6\%) de indivíduos considerados jovens. A existência indivíduos jovens de Phoradendron affine indica que os frutos produzidos estão sendo consumidos e dispersados por potenciais dispersores.[21,22]

Portanto, Phoradendron affine pode ter sido a primeira espécie de hemiparasita a ser dispersada entre as espécies arbóreas no parque do povo encontrando em Melia azedarach e Handroanthus avellanedae os hospedeiros ideais, e com a existência de aves dispersoras, facilmente se estabeleceu e proliferou em toda a área de estudo, sendo a quantidade de Phoradendron affine diretamente proporcional ao tamanho do hospedeiro.

\section{REFERÊNCIAS}

LIMA, V; AMORIM, M. C. C. T.. A importância das áreas verdes para a qualidade ambiental das cidades. Formação (Online), v. 1, n. 13, p. 69-82, 2011. 
FEIBER, S. D. Áreas verdes urbanas imagem e uso-o caso do passeio público de Curitiba-PR. RaegaO Espaço Geográfico em Análise, v. 8, p 93-105, 2004. https://doi.org/10.5380/raega.v8i0.3385

IBGE - Instituto Brasileiro de Geografia e Estatística. Censo Demográfico 2000. Disponível em: <http://www.ibge.gov.br>. Acesso em: 11 mai. 2017.

DA SILVA, T. C; TOMMASELLI, J. T. G. Estimativa do armazenamento de carbono das espécies arbóreas do parque do povo. Geografia em Atos (Online), v. 1, n. 7, p. 60-77, 2011.

DE BORTOLO, C. A. O espaço público do parque do povo- Presidente Prudente-SP: REFLEXÕES GEOGRÁFICAS. Geografia em Atos (Online), v. 1, n. 13, p. 50-65, 2013.

SCHALLENBERGER, L. S. et al. Avaliação da condição de arvores urbanas nos principais parques e praças do Município de Irati-PR. Revista da Sociedade Brasileira de Arborização Urbana, Piracicaba-SP, v. 5, n. 2, p. 105-123, 2010.

WHITE, B. L. A. et al. Análise da ocorrência de erva-de-passarinho na arborização da Universidade Federal de Sergipe, Campus de São Cristóvão, v. 41, n. 1, p. 1-8 2011.

VIEIRA, O. M. C. et al. Antimicrobial activity of Struthantus vulgaris (erva-depassarinho). Revista Brasileira de Farmacognosia, v. 15, n. 2, p. 149-154, 2005. https://doi.org/10.1590/S0102$\underline{695 \times 2005000200014}$

DA CONCEIÇÃO, G. M. et al. Erva-de-passarinho: substratos vegetais, uso e aplicações na medicina popular, Caxias, Maranhão. Scientia Plena, v. 6, n. 6, p. 15, 2010.

DETTKE, G. A; WAECHTER, J. L. Estudo taxonômico das ervas-de-passarinho da Região Sul do Brasil: II. Viscaceae (Phoradendron). Rodriguésia-Instituto de Pesquisas Jardim Botânico do Rio de Janeiro, v. 65, n. 4, p. 955-985, 2014.

MOURÃO, F. A. et al. Hospedeiras de Struthanthus flexicaulis (Loranthaceae) em campos rupestres ferruginosos no Quadrilátero Ferrífero, Minas Gerais. Lundiana, v. 7, p. 103-109, 2006.

CAZETTA, E; GALETTI, M. Frugivoria e especificidade por hospedeiros em Phoradendron rubrum Revista Brasil. Bot., V.30, n.2, p.345-351, 2007.

LEBLANC, M. L.; KIM, G; WESTWOOD, J. H. RNA trafficking in parasitic plant systems. Frontiers in plant science, v. 3, p. 203, 2012. https://doi.org/10.3389/fpls.2012.00203

LEAL, L; BUJOKAS, W. M; BIONDI, D. Análise da infestação de erva-de-passarinho na arborização de ruas de Curitiba, PR. Floresta, v. 36, n. 3, p. 323-330, 2006. https://doi.org/10.5380/rf.v36i3.7512

CAIRES, C. S. et al. Larval frugivory of Neosilba McAlpine (Diptera, Lonchaeidae) on Psittacanthus plagiophyllus Eichler (Santalales, Loranthaceae) in southwestern Mato Grosso do Sul State, Brazil. Revista Brasileira de Entomologia, v. 53, n. 2, p. 272277, 2009.

SULEVIS, C; BATISTA, D. B. Análise morfológica de espécies da arborização de ruas de Curitiba-PR e a infestação por erva-de-passarinho. Revista da Sociedade Brasileira de Arborização Urbana, v. 9, n. 2, p. 1-17, 2015. https://doi.org/10.5380/revsbau.v9i2.63111 
MARTINS, L. G. S. et al. Um estudo sobre a toxicidade da erva-de-passarinho (Struthanthus marginatus, Lorantaceae), parasitando trombeteira (Datura suaveolens, Solanaceae). Rev. Bras. Farm, v. 87, n. 2, p. 63-64, 2006.

PRESIDENTE PRUDENTE, P. M. Informações do Município de Presidente Prudente - SP. Disponível em: <http://www.presidenteprudente.sp.gov.br>. Acesso em: 01 mai. 2017.

RIGON, J. O gênero Phoradendron Nutt. (Viscaceae) no estado do Paraná, Brasil. Dissertação de Mestrado em Botânica, Universidade Federal do Paraná, 98 p., 2011.

CAIRES, C. S.; PROENÇA, C. E. B. Levantamento preliminar dos hospedeiros de Dendrophthora e Phoradendron (Santalaceae) no Distrito Federal, Brasil. Heringeriana, v. 2, p. 11-22, 2008.

ALVES, L. S. Frugivoria por aves em Phoradendron affine (viscaceae) nos municípios de Puxinanã e Campina Grande, Paraíba. Anais X Congresso de Ecologia do Brasil, 16 a 22 de Setembro de 2011, São Lourenço - MG.

OLIVEIRA, L. W.; SILVA, J. M. S.; DONZELLI, L.; SOUZA, V. H.; ANDRADE, J. Z. Levantamento ornitológico do "parque do povo", uma área urbana do município de Presidente Prudente - SP. Colloq Vitae. V. 07, n.2, p.26-33, mai-ago 2015. DOI: 10.5747 